post-hospitalisation for an AECOPD, is acceptable and feasible.

Methods A mixed method feasibility study was conducted including a parallel, two-group randomised controlled trial (RCT) (control group: usual $\mathrm{HaH}$ care; intervention group: usual care plus home-based exercise training) with convergent qualitative components (interviews: patients, family carers, researchers; focus groups: healthcare professionals [HCPs]).

Results 16/132 patients screened were recruited to the RCT with 8 allocated to each group and one withdrawn prior to receiving $\mathrm{HaH}$ care $(56 \%$ were male, mean [SD] age: 74 [9] years, median [IQR] $\mathrm{FEV}_{1}: 29$ [21, 40] percent predicted, $87 \%$ with an eMRC dyspnoea score of $4,5 \mathrm{a}$ or $5 \mathrm{~b}$ ). Four vs eight and four vs seven attended four week and three-month follow-up assessments in the control and intervention groups respectively. There was no evidence of contamination in the control group. $25 \%$ of patients allocated to the intervention group were unable to receive the intervention due to Covid19. The questionnaire-based outcomes were more complete and appeared more acceptable to patients than physical measures, with very poor uptake for physical activity monitoring via accelerometery. Qualitative findings (interviews: five patients, two family carers, four researchers; focus groups: PR and $\mathrm{HaH}$ service HCPs) demonstrated that trial and intervention processes were acceptable, clinically beneficial and safe, but did not explain the disparity between questionnaire-based vs physical outcome measure completion rates.

Conclusion The findings suggest an efficacy trial which investigates home-based exercise training integrated within a $\mathrm{HaH}$ service following hospitalisation for an AECOPD would be safe and acceptable to patients, family carers, HCPs and researchers alike, and is qualitatively felt to be of clinical benefit. However, additional piloting is required to optimise intervention fidelity and study processes given the low recruitment rates, high drop out of the control group and poor uptake of some physical assessments.

\section{S24 IS A NOVEL DIGITAL BREATHING \& ENERGY MANAGEMENT PROGRAMME EFFECTIVE IN REDUCING SYMPTOMS OF LONG COVID?}

J Moore, J Plumbe, N Hilliard, K Plumbe, N Beckett, T Burch, K Bahadur. Respiricare, Kent, UK

\subsection{6/thorax-2021-BTSabstracts.30}

Introduction The most common symptoms of 'Long COVID' which is defined as symptoms $>12$ weeks post COVID infection, are breathlessness and fatigue. Breathing retraining and holistic management for patients suffering with ongoing symptoms of COVID has been recommended to help manage these symptoms. ${ }^{1}$ Ensuring quality rest and activity energy management is essential for the management of chronic fatigue. ${ }^{1,2}$ The aim of this study is to investigate the effectiveness of a novel digital 6-week breathing \& energy group management programme for patients with Long COVID.

Method We conducted a pilot, cohort, observational study using qualitative questionnaires pre and post intervention between Jan -May 2021. The intervention was led by breathing, fatigue specialist physiotherapists and psychological wellbeing practitioners. Baseline information was gathered with an individual digital assessment. Participants were enrolled to weekly digital group sessions focusing on breathing retraining and establishing a good energy management balance. A follow up re-assessment was completed post intervention.

Results 72 participants aged between 24-81, 45 female,27 male, 57 White British, 7 Black British, 2 Black Asian, 6 Other Ethnicity were enrolled. Baseline data showed $87 \%$ $(n=63)$ had a breathing pattern disorder (Breathing Pattern Assessment Tool Score $>$ 4.) 69\% $(n=50)$ had signs of hyperventilation syndrome (Nijmegen score > 23). $77 \%$ were suffering with severe fatigue (Fatigue Severity Scale (FSS) $>5$ ). Outcome measures used were the Self-Reported Chronic Respiratory Disease Questionnaire (SR -CRDQ), General Anxiety Disorder 7 (GAD7), Patient Health Questionnaire PHQ9 and FSS. 86\% $(n=62)$ patients had a clinically significant improvement in at least 1 of the SR-CRDQ domains (breathlessness, emotion, fatigue and mastery).53\% $(\mathrm{n}=38)$ had a clinically significant reduction in FSS. 51\% $(n=37)$ patients had a clinically significant improvement in anxiety or depression.

Conclusion Analysis shows that a digital, novel 6 week breathing and energy management programme was beneficial for patients suffering Long COVID. Continued investigation and further research is required to evaluate the effectiveness of breathing retraining and energy management for patients suffering with Long COVID.

\section{REFERENCES}

1. George PM, et al. Respiratory follow-up of patients with COVID-19 pneumonia. Thorax 2020.

2. Updated NICE guidance on chronic fatigue syndrome. BMJ 2020.

\section{S25 CARDIOPULMONARY EXERCISE TESTING TO EVALUATE EXERCISE LIMITATION AND SHORTNESS OF BREATH IN LONG COVID}

L Godinho, T Wallis, D Levett, S Jack, T Wilkinson, B Marshall, A Banerjee, A Freemans. University of Southampton, Southampton, UK

\subsection{6/thorax-2021-BTSabstracts.31}

Introduction Approximately 10\% of COVID survivors experience long-term sequelae, with fatigue and exercise limitation most frequently reported. The physiological drivers of these symptoms remain unclear. Incremental cardiopulmonary exercise testing (CPET) is a routine clinical assessment used to evaluate exercise limitation but its utility in long COVID is unknown.

Methods Consecutive patients with non-hospitalised SARSCoV2 infection referred for standard-of-care CPET to investigate persistent exercise limitation were identified. Patient demographic and clinical information were extracted, and standard CPET parameters were collected and analysed. Ethical approval was obtained under the UHS REACT COVID observational database (REC-20/HRA/2986).

Results Nine patients were included in this pilot analysis. 55\% male, median (mdn) 47 years, 6 to 12 months post SARSCoV-2 infection. Reported pre-morbid exercise and fitness levels were above average. Patients demonstrated impaired exercise capacity, peak oxygen uptake $\left[\mathrm{VO}_{2}\right.$ peak $]$ (mdn $23.3 \mathrm{ml} / \mathrm{kg} /$ min, $81 \%$ predicted) and oxygen uptake at anaerobic threshold [AT] (mdn $13.4 \mathrm{ml} / \mathrm{kg}$. $/ \mathrm{min}$ ). AT as percentage of $\mathrm{VO}_{2}$ peak was reduced ( $\mathrm{mdn} 45 \%$ ) suggesting significant deconditioning. Oxygen-pulse $\left(\mathrm{O}_{2}\right.$ pulse) percentage predicted was reduced (mdn 80\%) suggesting impaired oxygen delivery and/or muscle oxygen utilisation (table 1). None of the patients demonstrated respiratory limitation to exercise. All patients had normal 
Abstract S25 Table 1 Preliminary CPET data for patients with persistent symptoms following non-hospitalised SARS-CoV2 infection, demonstrating reduced levels of aerobic fitness compared to $\%$ predicted, as assessed by oxygen uptake at peak exercise, oxygen uptake at anaerobic threshold (AT) and 02 pulse.

\begin{tabular}{llllll}
\hline $\begin{array}{l}\text { Patient } \\
\text { number }\end{array}$ & $\begin{array}{l}\text { Peak oxygen } \\
\text { uptake as\% } \\
\text { predicted }\end{array}$ & $\begin{array}{l}\text { Peak AT as\% } \\
\text { of peak oxygen } \\
\text { uptake }\end{array}$ & $\begin{array}{l}\text { 02 pulse } \\
\text { as\% } \\
\text { predicted }\end{array}$ & $\begin{array}{l}\text { VEVCO2 } \\
\text { slope }\end{array}$ & $\begin{array}{l}\text { Breathing } \\
\text { reserve } \\
\text { (litres/ } \\
\text { minute) }\end{array}$ \\
\hline 1 & 110 & 69 & 101 & 26.9 & 59 \\
2 & 70 & 31 & 76 & 22.6 & 138 \\
3 & 91 & 45 & 80 & 31.4 & 36 \\
4 & 108 & 63 & 93 & 28.1 & 84 \\
5 & 81 & 46 & 78 & 27.7 & 31 \\
6 & 81 & 44 & 82 & 26.4 & 71 \\
7 & 111 & 47 & 106 & 25.4 & 69 \\
8 & 61 & 33 & 70 & 27.5 & 96 \\
9 & 64 & 43 & 78 & 29.6 & 40 \\
\hline
\end{tabular}

baseline cardiac function. Six were referred for a Cardiac MRI after CPET, all of which demonstrated normal biventricular function.

Conclusions CPET provided an objective measure of functional limitation in our preliminary patient cohort, profound deconditioning was apparent. Given that our patient has normal cardiac function, it is possible that the reduction in $\mathrm{O}_{2}$ pulse reflects an intrinsic impairment in muscle oxygen utilisation. We have demonstrated similar patterns of exercise limitation in cancer patients undergoing chemotherapy, and subsequent improvements in their exercise training capacity following a 12 week personalised exercise training program. ${ }^{1}$ Exercise intervention studies are needed in these patients to determine optimal rehabilitation strategies.

\section{REFERENCE}

1. West, et al. Br J Anaesth. 2015;114(2):244-5.

\section{COPD exacerbations: prevention, treatment, recovery}

\section{S26 EFFECT OF SINGLE-INHALER EXTRAFINE BECLOMETASONE/FORMOTEROL/GLYCOPYRRONIUM PMDI (BDP/FF/GB) COMPARED WITH TWO-INHALER FLUTICASONE FUROATE/VILANTEROL DPI + TIOTROPIUM DPI (FLF/VIL+TIO) TRIPLE THERAPY ON HEALTH-RELATED QUALITY OF LIFE (HRQOL) IN PATIENTS WITH COPD: THE TRISTAR STUDY}

${ }^{1} \mathrm{M}$ Kots, ${ }^{2} \mathrm{G}$ Georges, ${ }^{1} \mathrm{~A}$ Guasconi, ${ }^{3} \mathrm{C}$ Vogelmeier. ${ }^{1}$ Chiesi Farmaceutici S.p.A., Parma, Italy; ${ }^{2}$ Chiesi USA, Cary (NC), USA; ${ }^{3}$ Klinik für Pneumologie, Marburg, Germany

\subsection{6/thorax-2021-BTSabstracts.32}

Rationale To evaluate the effect of single-inhaler extrafine $\mathrm{BDP} / \mathrm{FF} / \mathrm{GB}$ pMDI vs two-inhaler (FLF/VIL+TIO) triple therapies on HRQoL in patients with COPD to support market access dossiers in Europe.

Methods In this phase III, multicenter, randomized study patients received BDP/FF/GB 100/6/12.5 $\mu \mathrm{g}$ extrafine pMDI 2 inhalations BID or FLF/VIL 100/25 $\mu \mathrm{g} 1$ inhalation QD + TIO $18 \mu \mathrm{g} / \mathrm{d} 1$ inhalation QD for 26 weeks. The primary efficacy variable was the change from baseline in the St. George Respiratory Questionnaire (SGRQ) total score at Wk 26 in the intent-to-treat (ITT) and per-protocol (PP) populations, with non-inferiority defined as an upper confidence limit of the adjusted mean difference between treatments $<4$ units. Secondary endpoints included SGRQ response (defined as a decrease of $\geq 4$ units in total score), change in pre-dose $\mathrm{FEV}_{1}$ at Wk 26, and rate of moderate-to-severe COPD exacerbations over 26 weeks.

Results A total of 1157 patients were randomized (1095 completed), of whom $53.5 \%$ were $<65$ years of age, $75.5 \%$ males, $54.4 \%$ current smokers and $84.1 \%$ had 1 exacerbation in the past year. Baseline SGRQ total score was 52.8. In both groups the adjusted mean change from baseline in the SGRQ total score significantly decreased at Wk 26, with -6.77 for $\mathrm{BDP} / \mathrm{FF} / \mathrm{GB}$ and -7.82 for FLF/VIL+TIO in the ITT population. Non-inferiority was demonstrated in both ITT and PP populations, with an upper confidence interval of the adjusted mean difference below 4. SGRQ response rates at Week 26 were similar $(51.1 \%$ and $53.0 \%)$ and pre-dose $\mathrm{FEV}_{1}$ mean changes from baseline were 59 and $105 \mathrm{~mL} \quad(\mathrm{p}<0.001)$. Adjusted rate ratio was $1.086(\mathrm{p}=0.525)$ for moderate-tosevere exacerbations and 0.568 for severe exacerbations $(\mathrm{p}=0.068)$. Serious TEAEs occurred in $39(6.7 \%)$ and 56 $(9.7 \%)$ in each group, respectively.

Conclusion Treatment with BDP/FF/GB extrafine pMDI for 26 weeks significantly improved HRQoL as measured by the SGRQ and was non-inferior compared to FLF/VIL+TIO. Lung function improved with both treatments but more so with FLF/VIL+TIO whereas a larger reduction in severe exacerbations occurred with extrafine $\mathrm{BDP} / \mathrm{FF} / \mathrm{GB}$. Both treatments were safe and well tolerated.

Please refer to page A188 for declarations of interest related to this abstract.

\section{S27 ARE PATIENTS WITH COPD MORE ADHERENT TO FLUTICASONE FUROATE/UMECLIDINIUM/VILANTEROL (FF/UMEC/VI) COMPARED WITH MULTIPLE-INHALER TRIPLE THERAPY IN A REAL-WORLD UK PRIMARY CARE TREATED POPULATION?}

${ }^{1} \mathrm{DMG}$ Halpin, ${ }^{2} \mathrm{KJ}$ Rothnie, ${ }^{3} \mathrm{~V}$ Banks, ${ }^{2} \mathrm{~A}$ Czira, ${ }^{2} \mathrm{C}$ Compton, ${ }^{3} \mathrm{R}$ Wood, ${ }^{3} \mathrm{~T}$ Tritton, ${ }^{3} \mathrm{O}$ Massey, ${ }^{3} \mathrm{R}$ Wild, ${ }^{4} \mathrm{~N}$ Snowise, ${ }^{2} \mathrm{E}$ Gubba, ${ }^{2} \mathrm{R}$ Sharma, ${ }^{5} \mathrm{AS}$ Ismaila, ${ }^{6} \mathrm{CF}$ Vogelmeier. ${ }^{1}$ University of Exeter Medical School, Exeter, UK; ${ }^{2}$ GlaxoSmithKline PIC, London, UK; ${ }^{3}$ Adelphi Real World, Bollington, UK; ${ }^{4}$ Kings College, London, UK; ${ }^{5}$ GlaxoSmithKline Plc, Collegeville, USA; ${ }^{6}$ University Medical Center Giessen and Marburg, Marburg, Germany

\subsection{6/thorax-2021-BTSabstracts.33}

Background and Objectives Triple therapy with inhaled corticosteroid, long-acting muscarinic antagonist and long-acting $\beta 2$ agonist (ICS/LAMA/LABA) is recommended for patients with COPD who continue to experience exacerbations on dual therapy (LAMA/LABA or ICS/LABA). Adherence to multipleinhaler triple therapy (MITT) has previously been shown to be inadequate. Single-inhaler triple therapy, such as fluticasone furoate/umeclidinium/vilanterol (FF/UMEC/VI), may improve adherence due to decreased treatment complexity. This study investigates the real-world comparative adherence to FF/UMEC/ VI vs any MITT combination in UK patients with COPD.

Methods This retrospective analysis of linked UK primary and secondary care data (Clinical Practice Research Datalink [CPRD] Aurum; Hospital Episode Statistics [HES]) indexed patients with COPD on the first prescription of FF/UMEC/VI 